XTOD to Conventional Facilities Interface Control Document

D. McMahon

October 24, 2005 
This document was prepared as an account of work sponsored by an agency of the United States Government. Neither the United States Government nor the University of California nor any of their employees, makes any warranty, express or implied, or assumes any legal liability or responsibility for the accuracy, completeness, or usefulness of any information, apparatus, product, or process disclosed, or represents that its use would not infringe privately owned rights. Reference herein to any specific commercial product, process, or service by trade name, trademark, manufacturer, or otherwise, does not necessarily constitute or imply its endorsement, recommendation, or favoring by the United States Government or the University of California. The views and opinions of authors expressed herein do not necessarily state or reflect those of the United States Government or the University of California, and shall not be used for advertising or product endorsement purposes.

This work was performed under the auspices of the U.S. Department of Energy by University of California, Lawrence Livermore National Laboratory under Contract W-7405-Eng-48. 


\begin{tabular}{|lr|l|l|c|}
\hline $\begin{array}{l}\text { LCLS } \\
\text { Interface Control Document \# }\end{array}$ & $1.5-508$ & $\begin{array}{l}\text { XTOD - } \\
\text { Conventional } \\
\text { Facilities }\end{array}$ & Revision & 0 \\
\hline
\end{tabular}

\section{XTOD to Conventional Facilities Interface Control Document}

Donn McMahon Author

XTOD Project Engineer

Signature Date

Richard Bionta

XTOD WBS Manager

Signature Date

David Saenz

Conventional Facilities Manager

Signature Date

Jim Welch

Physicist, Conventional Facilities

Signature Date

Darren Marsh

Quality Assurance Manager

Signature Date

Mark Reichanadter

Chief Engineer

Signature Date

John Galayda

Project Director

Signature Date

Change History Log

\begin{tabular}{|l|l|l|l|}
\hline $\begin{array}{l}\text { Rev } \\
\text { Number }\end{array}$ & $\begin{array}{l}\text { Revision } \\
\text { Date }\end{array}$ & $\begin{array}{l}\text { Sections } \\
\text { Affected }\end{array}$ & Description of Change \\
\hline 000 & $9-28-05$ & All & Initial Version \\
\hline & & & \\
\hline & & & \\
\hline
\end{tabular}




\section{EXECUTIVE SUMMARY}

1.1 Scope This document describes the interface between the LCLS X-ray Transport and Diagnostics (XTOD) (WBS\# 1.5) and the LCLS Conventional Facilities (CF) WBS $\# 1.1$ ). The interface locations ranging from the beam dump to the far experimental hall are identified. Conventional Facilities provides x-ray, beamline and equipment enclosures, mounting surfaces, conventional utilities, compressed (clean, dry) air, process and purge gases, exhaust systems, power, and environmental conditions for the XTOD components and controls.

\subsection{Responsibilities}

\begin{tabular}{|c|l|l|}
\hline WBS & Represented by & \multicolumn{1}{c|}{ Responsible for: } \\
\hline 1.5 & R. Bionta & Supporting and approving this ICD \\
\hline 1.9 & D. Saenz & Supporting and approving this ICD \\
\hline 1.5 & D. McMahon & Preparing, maintaining, and approving this ICD \\
\hline
\end{tabular}




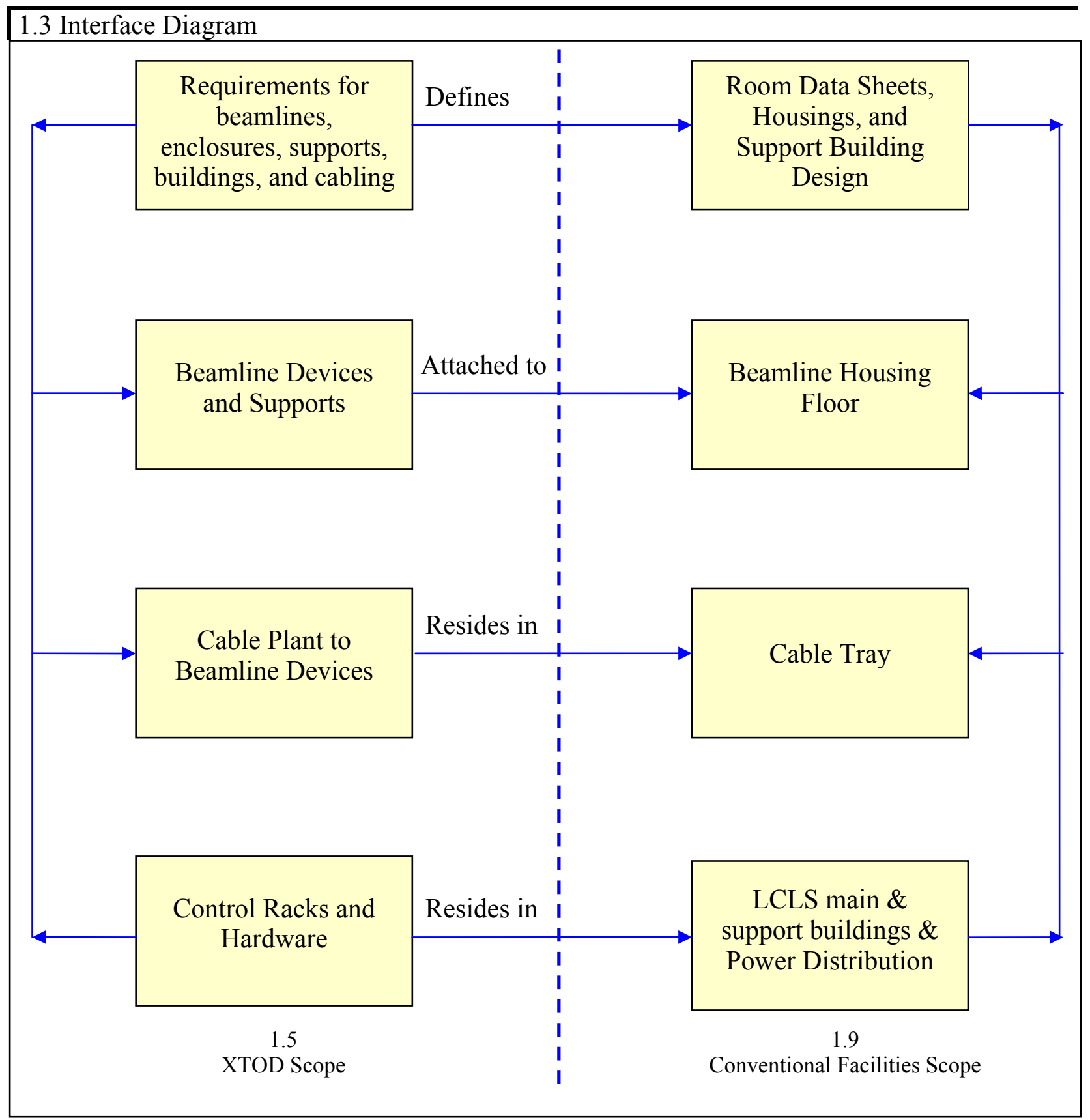




\begin{tabular}{|c|c|c|c|}
\hline $\begin{array}{c}\text { Headi } \\
\text { ng }\end{array}$ & Check & Type & Location and Description \\
\hline 3.1 & $\mathrm{X}$ & Mechanical & Mounting surface/footing for component support \\
\hline 3.2 & $\mathrm{X}$ & Fluid & Compressed air, purge and process gases \\
\hline 3.3 & & Vacuum & \\
\hline 3.4 & $\mathrm{X}$ & Thermal & Enclosure isolated from outside environment \\
\hline 3.5 & & RF & \\
\hline 3.6 & $\mathrm{X}$ & Electrical & $\begin{array}{l}\text { Power distribution to racks, ground connections, convenience } \\
\text { outlets and lighting, }\end{array}$ \\
\hline 3.7 & $\mathrm{X}$ & Power & Power for racks, convenience outlets and lighting \\
\hline 3.8 & $\mathrm{X}$ & Signal & Interlocks to PPS \\
\hline 3.9 & $\mathrm{X}$ & Radiation & Electrons, X-Rays \\
\hline 3.10 & $\mathrm{X}$ & Environmental & Ventilation, HVAC \\
\hline 3.11 & & Other & \\
\hline
\end{tabular}

\subsection{Applicable Documents}

1.1-101 LCLS Cable Specifications

1.5-001 XTOD Physics Requirements

1.9-001 Physics Requirements for Conventional Facilities

1.9-100 Shielding Requirements for the LCLS Project (Title I)

1.9-101 Architectural/Engineering Design Guidelines

1.9-102 Generic Accelerator Tunnel Construction Tolerance Specification

1.9-104 Emergency Lighting Specification

FEE, NEH, Tunnel, and NEH Room Data Sheets

\subsection{Interface Definition}

The interface between the LCLS XTOD and Conventional Facilities Systems occurs all along the physical expanse of the Front End Enclosure, Near Experimental Hall, Tunnel, Far Experimental Hall, and surface Equipment Shelters. CF provides the beamline housing structures in which the XTOD components are mounted. CF also provides all cable trays, water headers, air headers, process and purge gas headers, exhaust system headers, convenience outlets, lighting, power distribution for electrical equipment racks and XTOD components, and HVAC as required for equipment in the FEE, Tunnel, and NEH. CF also upgrades utilities as required in existing housings and support buildings as required for the XTOD beamline and controls.

The XTOD System installs components and systems within the structures provided by Conventional Facilities. The interface varies with type of component. XTOD installs the cable plant into cable trays installed by CF. CF installs anchors, per XTOD specifications, in order to mount beamline components and equipment. XTOD installs racks in equipment shelters and FEE, Tunnel, NEH, and FEH locations provided by CF. CF provides network, power distribution and ground connections to the process racks. XTOD will specify the power requirement. CF provides compressed air, process and purge gas, and exhaust system headers

ICD 1.1-50?-r0

5 of 7
Check the LCLS Project website to verify that this is the correct version prior to use. 
with valves at locations specified by XTOD. XTOD provides specifications to CF on, internal enclosure dimensions, cable tray dimensions and routing and gas, power, temperature and humidity requirements. Shielding requirements will be provided by the SLAC Radiation Physics department based on electron beam requirements. XTOD also requires review of the implementation of LOTO and Fire Protection/Life Safety design in the power distribution.

3.1 Mechanical Requirements - Mechanical interfaces are at the housing floor for beamline devices, housing floor for process equipment rack mounting, housing walls for beam transport pipes, power connection at each process equipment rack for power distribution, cable tray for cable plant installation, nipples at valves for water distribution and nipples at valves for air, process, and purge gas distribution, and trunk headers for exhaust systems.

3.2 Fluid Requirements - Compressed air, process and purge gas, and exhaust headers provided by CF with valve locations specified by XTOD. XTOD provides HVAC requirements.

\subsection{Vacuum Requirements - None}

3.4 Thermal Requirements - The enclosure provided by CF will form a thermally controlled volume for the FEE and the NEH hutches.

\subsection{RF Requirements - None}

3.6 Electrical Requirements - Cabling providing power to distribution panels and beamline in the FEE, NEH, Tunnel, and FEH will be installed by CF. CF to provide certified electrical ground connections throughout the FEE, NEH, Tunnel, and FEH. Cabling from process racks to beamline equipment will be installed by XTOD (or Controls Department). All cable trays are to be installed by CF. XTOD will provide cable tray dimensions and routing diagrams for tray to XTOD components and systems. Cabling requirements to conform to the LCLS specification, "1-101 LCLS Cable Specifications".

3.7 Power Requirements - CF to provide power to distribution panels. CF will also provide convenience outlets and welding power outlets. XTOD will provide power requirements.

3.8 Signal Requirements - XTOD will provide signals from requisite XTOD systems to the PPS to turn off housing lights and power to hazards. CF will provide networking for XTOD controls.

3.9 Radiation Requirements - CF to provide housing wall thickness and geometry to meet radiation shielding. Shielding requirements will be provided by the SLAC Radiation Physics department based on electron beam requirements. Radiation shielding to conform to the LCLS specification, "1.9-100 Shielding requirements for the LCLS Project". 
3.10 Environmental Requirements - CF to provide ventilation in FEE, Tunnel, and NEH. $\mathrm{CF}$ to provide air conditioning in FEE and NEH.

\subsection{Other Requirements - None.}

4.0 Verification - Verification of all requirements to be performed during system commissioning. Performance goals for each system to be tested are described in the Physics Requirements Documents.

5.0 Notes - Construction of global controls feedback and controls infrastructure to be managed and funded from WBS 1.1 LCLS Management and Integration. 